\title{
The Harmonious Co-prosperity of Local Traditional Economy and New Airport Economy--Research on Urban Planning of Chaoshan Airport Economic Zone
}

\author{
Jiemin Liu
}

Chinese Traffic Estate Co.Ltd, Beijing, China

Pengjun Zhao

Peking University, Beijing, China

Gang Tian

Beijing Qinghua Tongheng planning design and Research Institute Co., Ltd., Beijing, China

\begin{abstract}
Constructing the airport economic zone and developing the air economic industry can swiftly promotes the city's industrial level and greatly improves the comprehensive competitiveness of the city. Chaoshan airport which is built by Jieyang city is the third largest main airport in Province Guangdong .The future air economic zone will definitely exert an vital influence on the expansion of urban spatial pattern and the upgrade of the urban economy. As the city's economy is primarily supported by the local traditional industry, which has little relationship to the airport economy, the foundation of building an airport economy zone is weak. Jieyang faces the contradiction between the development of the traditional industry and the opportunity of introducing the new high-tech industry. In this paper, a "double incubators" mode is proposed to deal with the space layout and the industry introduction. On one hand, It is suggested that Jieyang teams up with brother cities--Chaozhou and Shantou--to build six industrial parks named "the incubator of transforming and upgrading local traditional industries" which aim at supporting local outstanding enterprises. For the other part, Jieyang can combine with Guangzhou, Province Taiwan and Asean countries to built "the incubator of the high-tech industry in the airport zone" and "the incubator of the equipment manufacturing industry in the river harbour zone". In addition, the government can guide the low end of the local enterprises which exist in the airport economic zone for a "smart concession"with a variety of policy measures.As for the introduction and prosperity of the service industry in the zone, a "double centers mode" will be established to promote the upgrading of Jieyang's municipal facilities center and the cultivating of thefuture Chaoshan area's service center.
\end{abstract}

KEYWORD: Jieyang city; Chaoshan metropolitan; airport economic zone; the incubator

\section{THEORY BASE}

After many years' pre-occupation with ideological battles and political correctness, Chinese government has finally altered its path to the pursuit of economic growth. To work out a development strategy that stimulates growth and to expand the revenue base are two essential goals for local governments, as any of their political and economic goals depend on the revenues derived from the local economy. The arena of urban development is made more intriguing by the commodification and marketization of land and property since 1988 which have obviously created landed interests. The users of stake land make use of their status as de facto owners of land they do not actually own to seek "rents", and property developers are the actors who actively materialize gains from land property development (Zhu, 1999). Local government has its own stake in revenue generation from local growth in order to sustain and consolidate itself in political field.

According to Turok (1992), property development refers to "the assembly, land, building materials and labour to produce or improve buildings for occupation and investment purposes. Primary thrust of the policy was to achieve urban regeneration through attracting assisting investment by the private sector in property development (Healey, Davo Toole, Usher, \& Tavsanoglu, 1992, p.277).

To attract private investment, various forms of public support were provided in the urban regeneration process (Healey, 1991). Expecting to raise capital, generate jobs, and improve other local assets through property development, the public sector creates and opens markets though the coordination of development activities, land assembly, subsidy providing, and risk minimization, while the private sector follows up the opportities (Healy etal., 1992). Property interests have been 
recognized as the central element in the formation of growth coalitions within the redevelopment processes (Harding, 1992).

Local state takes on the role of a place promoter that aims at enhancing place-based competitiveness form intervention. This form of intervention requires collective and strategic action, which lays the foundation for new urban planning. Planning has changed from being based on technical feasibility and physical design standards to the declaration of economic and development goals. Thus the aim of the city plan has changed from serving production and facilitating the lives of the working class to enhancing economic competitiveness, branding place, and serving inward investment. Consequently, the style of loan has shifted from blueprint to strategic statement and policy recommendations. Overall, the transformation of city plans reflects the different functionality of loanning -from producing internal government documents and development guidelines and coordinating different economic sectors to producing statements, slogans, and policy recommendations, coordinating lower governments under the municipality such as districts and suburban counties, and providing jusitifications for exceeding national standards. Planning thus became more visionary to fulfill the following functions: conceptualizing the urban future; initiating economic restructuring; and promoting strategic infrastructure development to enhance competitiveness (Wu 2007).

The traditional master plan which is in essence a physical design attached to the overall economic planning system. With the retreat from direct resource distribution, the local state has begun to shift its role from the organizer of economic production to that of urban development. Marketization of the means of production has led to intercity competition. Local governments are driven by the need to capture mobile resources. In order to do so, the inhancement of local competitiveness has become the top priority. Conventional physical loanning is thus no longer suitable for this new functionality of strategic management. Since 2000, a new type of planning instrument has emerged called the concept plan or strategic development plan. It is a highly flexible instrument and is not constrained by national planning standards. The preparation is entirely optional and self-funded by the local government, which defines the requirement according to its own needs. Consquently, the strategic development loan is more flexible and less constrained by existing planning regulations, In fact, there is no standard procedure to guide its preparation. Rather than a legal or administrative guidance, the strategic development plan is an expression of the long-term vision of the political elite. The strategic plan of the Chanshan airport economic zone in the following sections is an example.

\section{RESEARCH BACKGROUND}

The airport economic refers to a kind of industrial aggregation which puts the airport as the carrier,the air transportation as the core, the high-tech service industry and advanced manufacturing as the composition and directly serves or relates to the air transportation. The airport economic zone, which constitutes by the industrial clusters with obvious connections to aviation hub, has been a core region of a large number of new rised international economic center cities.

Some developed cities in Europe and America take the lead to develop the mixed functional and high-level economic zones, such as Dutch Amsterdam Schiphol airport economic zone, Frankfurt international airport economic zone, Egyptian Memphis international airport economic zone, South Korea's Incheon airport economic zone, Atlanta international airport economic zone, etc.

These airport economic zones which site around the international airports, develop the aviation industry in the adjacent to the airport, as well as high level and added value industry and all kinds of modern service industry (as is shown in table 1).

Chinese air economy has been in a high-speed developing stage. Some first and second tier cities have carried out the planning and constructing of the air economic zone projects, such as Beijing, Chongqing, Nanjing, Hangzhou, Ningbo and Wuxi. Some of them have accomplished initial results. Chaoshan metropolitan region has made its local traditional industry as the pillar of its economy, which has little relationship with the air economy but still faces the need of grasping some opportunity to transform and upgrade as well. Jieyang is a thirdtier city which is in the middle stage of industrialization and which has limited economic strength. How to deal with the contradiction of the current situation and the future potential opportunity when meeting the new airport? That requires innovative ideas to guide the future space layout and the industry trends.

\section{THE PRESENT SITUATION AND THE FUTURE AIR ECONOMIC BASE OF CHAOSHAN METROPOLITAN}

\subsection{The industrial structure is constituted mainly by the local private industry, which has limited relationship to the air economy.}

Chaoshan metropolitan is an area which is supported by developed local traditional industry. In 2011, the metropolitan has reached 19379 Yuan per capita GDP, and the ratio of agriculture, industry and service industry is $8: 55: 37$. According to the data above it can be seen that, the area is in the middle phase of industrial development. In the industrial 
output, the ratio of light industry and heavy industry is 65:35.Local private enterprises occupy a dominant position in the cities' industrial structure. Chaoshan district has a huge number of active private enterprises which are the main force and backbone of the economic development, investment in fixed assets, exportation and technological innovation. In 2010 the added value of private economy is 173 billion, which accounts for $62.4 \%$ of GDP and is far higher than the average of $43 \%$ in Guangdong province. The number of private enterprises above designated size also accounted for over $90 \%$ of the total number of enterprises. The product type producing by local private enterprises, constitutes mainly by local traditional advantage products with low technology, such as textile, plastic, metal, food production, etc. Most of its products use highway transportation, railway transportation and shipway transportation for their material input and products output due to their low value and too big volume.

Table 1 Classification of large foreign international airport economic zone

\begin{tabular}{|c|c|c|}
\hline $\begin{array}{l}\text { Airport industry } \\
\text { classification }\end{array}$ & Explaination & Detailed classification \\
\hline \multirow{3}{*}{$\begin{array}{l}\text { Aviation core } \\
\text { industry }\end{array}$} & \multirow{3}{*}{$\begin{array}{l}\text { Refers to the industry which directly uses the airport } \\
\text { facilities and service resources to carry out production. }\end{array}$} & Aviation transportation industry \\
\hline & & Aviation logistics industry \\
\hline & & Airport service industry \\
\hline \multirow{5}{*}{$\begin{array}{l}\text { Aviation related } \\
\text { industry }\end{array}$} & \multirow{5}{*}{$\begin{array}{l}\text { Refers to the industry which are highly sensitive to the air } \\
\text { transportation service. It has an urgent need of the swift and } \\
\text { convenient passenger and cargo logistics which can be } \\
\text { supplied by the aviation. }\end{array}$} & Aerospace manufacturing industry \\
\hline & & New and high technology manufacturing \\
\hline & & Light products manufacturing \\
\hline & & Modern agriculture \\
\hline & & $\begin{array}{l}\text { International business convention and } \\
\text { exhibition industry }\end{array}$ \\
\hline \multirow{4}{*}{$\begin{array}{l}\text { Aviation } \\
\text { supporting } \\
\text { industry }\end{array}$} & \multirow{4}{*}{$\begin{array}{l}\text { Refers to the service industry such as accomodation, } \\
\text { education, consumption, shopping, entertainment, etc., as } \\
\text { well as supporting industry such as research,training,finance, } \\
\text { agents and advertising which relies on the passenger and } \\
\text { cargo flows that are generated by the air transportation, the } \\
\text { aviation core industry and the aviation related industry. }\end{array}$} & Educational and scientific research industry \\
\hline & & Accommodation and catering industry \\
\hline & & Entertainment and leisure industries \\
\hline & & Financial and advertising industry \\
\hline
\end{tabular}

\subsection{The local private enterprises which base on the specialized towns as the carrier face the bottlenecks and need to grasp some new opportunity to transform and upgrade.}

By 2011, there are 54 specialized towns which are main carriers of the industrial clusters accounting for more than $50 \%$ economic output of Chaoshan metropolitan area. However, the mode of specialized town is faced with many problems in the process of development. The industrial clusters are constituted mainly by small and medium sized enterprises, which produce low cost, low benefits, low technology content, and low prominent advantage products. Factories just gather together to form a cluster. There is no R\&D or service center for public use. The enterprises compete with each other fiercely rather than forming a complete upstream and downstream industry chain. There is a huge demand of exploring the outer market as the local market is extremely limited. The local entrepreneurs express urgent hope that the new airport economic zone can provide a platform and indicate the direction for the local industry to transform and upgrade.

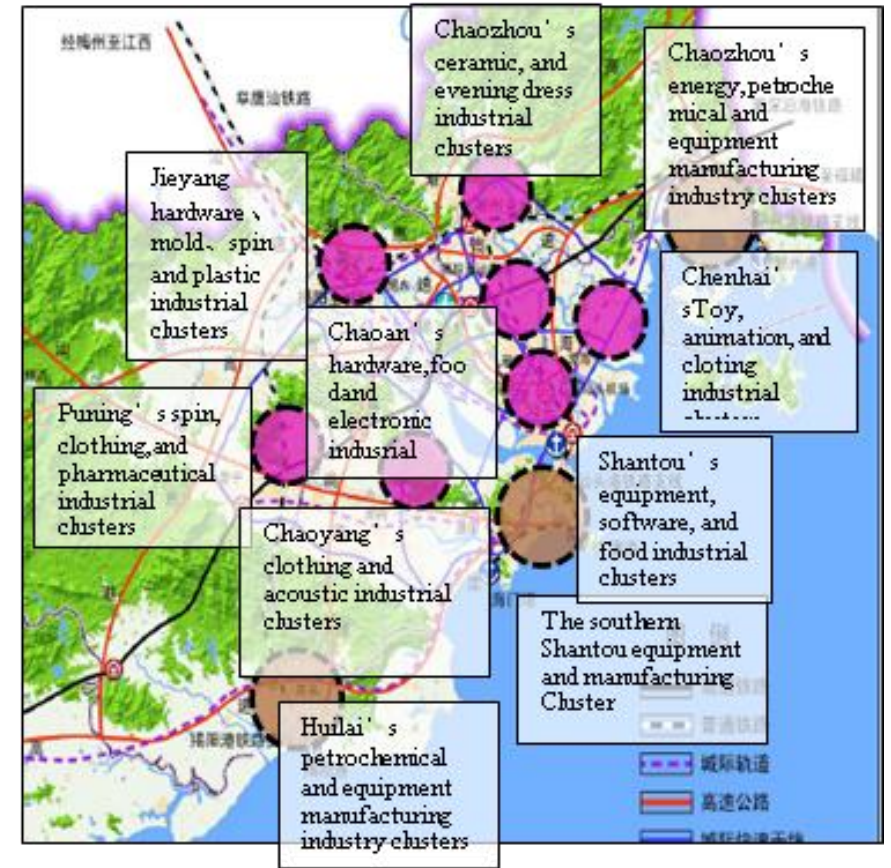

Figure1 The main traditional industrial clusters of Chaoshan metropolitan

\subsection{For the high-tech industry which relies on the airport economic zone, the foundation of the city is weak.}

For the study of the foreign successful cases, it can be seen that the air economy needs industry and 
service with close relationship to airport to support. However, the condition of swiftly introducing and cultivating the high-tech industry and service which needs huge amount of financial support, technical support and senior technical personnel is not enough. Obviously, it is unrealistic to just rely on the stimulating of airport and the strength of Jieyang city alone to develop this kind of industry. But if the industry is not introduced just because of the limitation, the great opportunity of pushing the city's economy to a full upgrading will miss. As a result, an innovative developing mode needs to be carefully designed.

\section{THE STRATEGY OF THE PLANNING AND THE INDUSTRY INTRODUCING OF JIEYANG AIRPORT ECONOMIC ZONE}

\subsection{The overall strategy}

As for the overall strategy, there are two factors which should be into consideration. For one part, an innovative and effective method to introduce the high-level industry should be put forward .For the other part, the local demand of upgrading the traditional industry and city's public service facilitiesneeds to be into accounted for so that the local entrepreneurs and citizens can shared the results of the air economic zone's development. For that purpose, a "double incubators" mode and a "double centers" pattern needs to be put forward.

\subsection{The first strategy: Set aside the landscape excellent and the ecological sensitive land,so that the overall pattern of land use can be defined}

Before the construction landuse planning, the land with excellent landscape and sensitive ecology needs to be set aside, so that its original characteristics could be kept. The most important part is to protect the core area of Mountain Sanpu, and the bank area of River Rong.Mountain Sanpu is the mother mountain of Chaozhou, Shantou and Jieyang, as River Rong is the mother river. For one part, the beautiful landscape will lay a good foundation of the city's future tourist industry, commercial industry and high-tech industry; For the other part, it forms a cultural tie for the cities' future cooperation.

\subsection{The second strategy: the design of "the double incubators" mode.}

\subsubsection{Establish "the incubator of transforming and upgrading the traditional industry" with the help of Shantou and Chaozhou.}

In order to get the powerful support of brother cities Chaozhou and Shantou, and help the traditional industrial clusters grow up, transform and upgrade, "the incubator of transforming and upgrading the local traditional industry"is supposed to be established. There are six industrial parks, which includes the senior clothing design and manufacturing industrial park, the high-tech toys cartoon $\mathrm{r} \& \mathrm{~d}$ and manufacture industrial park, the materials and seiko stainless steel r\&d and manufacture industrial park, the high-tech ceramic r\&d and manufacture industry park, the high-tech food $r \& d$ and manufacture industrial park, chemical industry $r \& d$ and manufacture park. These industrial parks aim at the local traditional industrial clusters which are most famous, powerful and which may have some relationship to the airport economic zones. The incubator can use the favoured policy to introduce the best local enterprises into parks to cultivate. The support and cultivate policy are as follows: Providing the land with perfect infrastructure and public service facilities, the sustainable fanancial insurrance, political support, such as low tax policy, technical training, etc.

The requirement of the companies getting into the incubator are as follows: The enterprises should be chosen from the specific industrial clusters in the metropolitan. The scale of the corporation should meet the required size. The future developing direction will be in a close relationship to the airport economy. The products need to have a strong ability of independent innovation, technical content and a certain brand awareness.

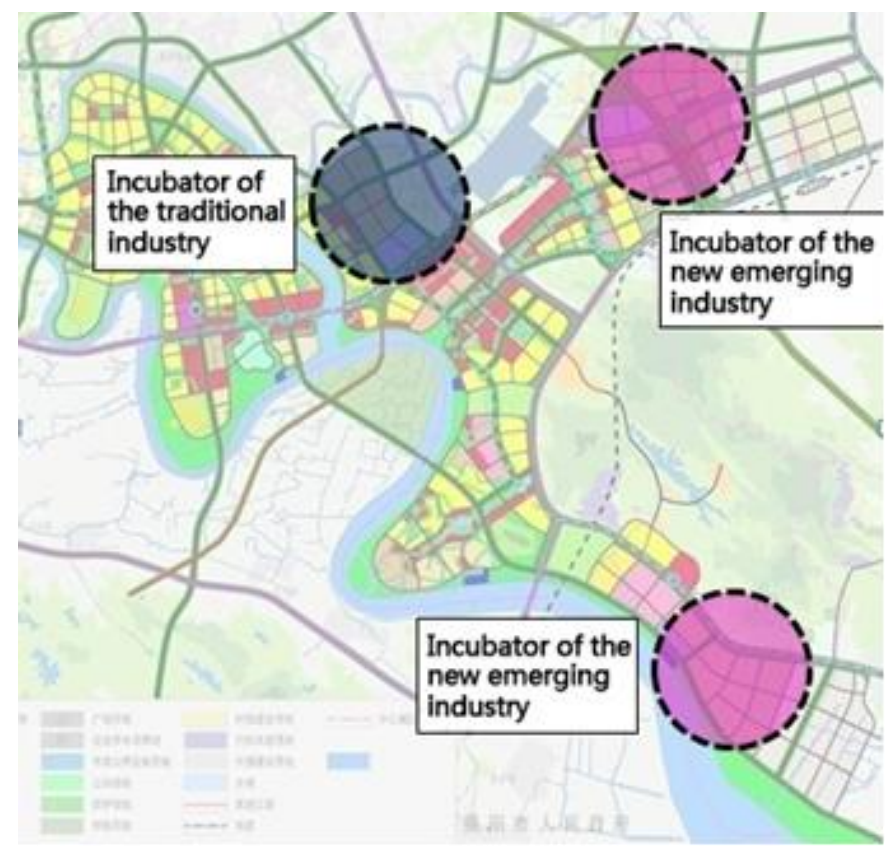

Figure2 The Layout Mode Figure of "double incubator "

The government can carry out the investment promotion activities, which aims at the local companies in Chaoshan area. Enterprises can participate in bidding for the government and the expert to choose. For the enterprises which are chosen out, the government can formulate some special politics to gradually cultivate until they have 
national or even international market competitiveness. Besides, the beneficial politics which can be used in the incubator will stimulate the whole industrial clusters to transform and upgrade. Furthermore, this mode will also combine brother cities Chaozhou and Shantou to work together to support the building the airport economic zone.

\subsubsection{Establish "the incubator of high-tech industry in airport zone" and "the incubator of equipment manufacturing industry in river harbor zone" with the help of the surrounding area cities, provinces and asean countries}

In order to compensate the shortage of the high-tech industry and modern service in Chaoshan area and to blend into the globe background of multinational companies entering in and domestic industry transforming, the development of new air economy is in urgent need. For that reason, two incubator industrial parks can be developed. They are "the incubator of hign-tech industry by airport" and "the incubator of manufacturing industry by river pork."

In order to compensate the shortage of the hightech industry and modern service in Chaoshan area and to blend into the globe background of multinational companies entering in and domestic industry transforming, the development of new air economy is in urgent need.For that reason,two incubator industrial parks can be developed.They are "the incubator of hign-tech industry by airport" and "the incubator of manufacturing industry by pork."

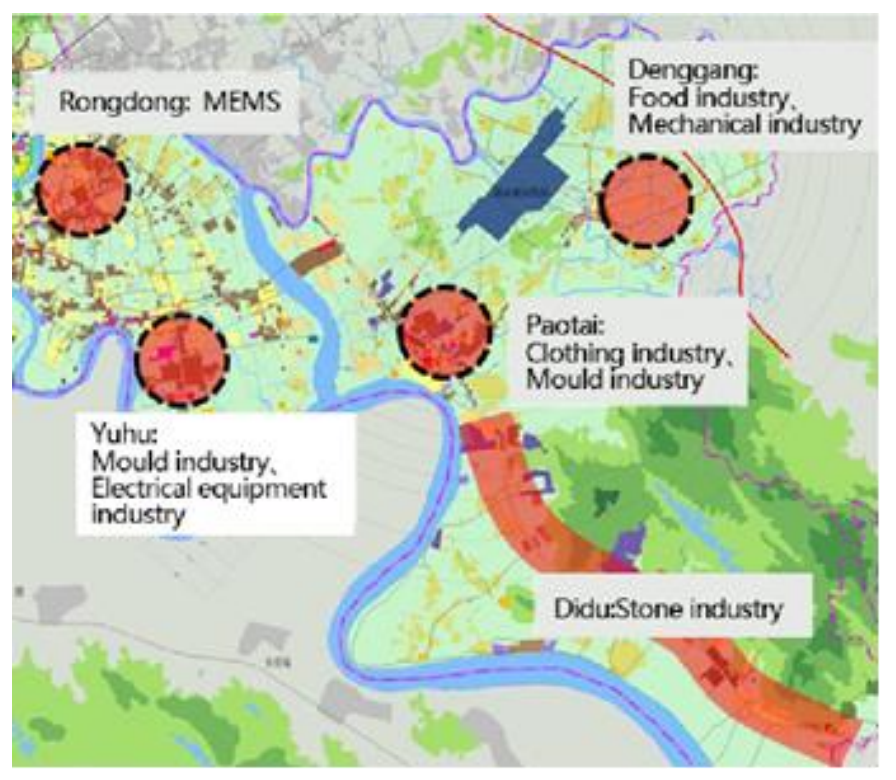

Figure 3: The main existing industrial clusters in the air economic zone

Considering the large amount of low-tech labour in the local economy and the limitation of the environmental capability, the chosen of the industrial categories should be with close upstream or downstream relationship to the local industry, with strong employment ability, effective import and export promotion ability, and meet the requirements of sustainable development. The chosen out industrial categories are as follows: the communication equipment manufacturing industrial park, the computer manufacturing industry park, the electronic measuring instruments manufacturing industrial park, the electronic components manufacturing industry park, the pharmaceutical industry park and the medical equipment and instruments industry park for "incubator of the hightech industry" by airport, the transportation equipment manufacturing industrial park for "incubator of the manufacturing industry" by the river bank.

In order to accumulate the strength, Jieyang needs to invite brother cities including Shantou and Chaozhou, as well as the provincial capital city Guangzhouto cooperate. At the same time, Jieyang can actively contact the surrounding developed areas and countries, such as Province Taiwan and asean countries together for the building of the industrial parks.

\subsubsection{The "smart concession" of the existing low- ended industries in the airport economic zone}

There are plenty of lowend enterprises in the core area of the airport economic zone which is located in Yuhu Distrct, Didu Town, Dengang Town, and Paotai town. The level of these enterprises are far away from the air economic. With the development and expansion of airport economic zone, the air economic industry are more competitive than the local low-end industry which could easily replaces the other. For the purpose of protecting the interests of the large number of the local enterprises effectively, the plan proposes to establish a special industrial park in outlying area of the airport economic zone to gather these low-end enterprises together. In this way the higher value land of the core area can be set aside. Then in the later period, government can take a variety of ways to help these low-end enterprises to get a "smart concession", such as encouraging mutual merger to build leading companies, encouraging the traditional enterprises to become a shareholder of emerging enterprises, or be purchased by the local government.

\subsection{The third strategy: "the double centers mode" of the service industry}

As the area lies in the intermediate depression between the Pearl River Delta and the two main functional areas of Haixi, the service sector is still in the stage of less advanced. In order to effectively capture the commanding heights of modern service industry development of Chaoshan metropolitan region, we should firmly grasp the connotation of airport economic and the portal of economic and trade cooperation between Guangdong or even the 
southwest provinces and Taiwan Province. It should be fully taken into account that this area is adjacent to the Asean region, but is also a famous hometown of overseas Chinese, and has other advantages including humanities and geography, thus it should effectively introduce the service industry which contacts close with airport economy and can enhance the level of services of the metropolitan area, thereby promoting the upgrade of the status of the entire metropolitan area around Chaoshan.

However, before the completion of comprehensive construction of industrial parks based on "the double incubator" mode, it is very difficult to directly construct a new regional modern service center in the airport economic zone. As a result, in the early stages of planning, we can take 'the first estward' of Jieyang city as a primary objective, and build a new municipal service center firstly in the Yuhu Area to synchronously service for the development of airport economic zone; after the gradual construction of "the double incubators", then the airport economic zone needs the support of a high level modern service center.At that time, we should gradually improve the construction of the new regional center to form a "double center" pattern of a regional center and a new municipal center, thereby ensuring the coordination of the development of Jieyang city and the development of Airport Economic Zone.

\subsubsection{The building of municipal service center of Yuhu district and the development of local tourism industry}

In order to successfully achieve "the first estward" of Jieyang City, Yuhu district can start from the relocation of the political center, and guide the development of a commercial center, then gradually introduce real estate industry, make construction of service facilities including supporting education, health care, leisure and entertainment, etc. At the same time, relying on the important landscape including the three cities' "Mother Mountain" Sangpu Mountain and the "Mother River" Rongjiang, and combing the renovation of Rongjiang east coast landscape and the development of local tourism industry, Jieyang can create new $\mathrm{Yu}$ lake city with high positioning, complete development of the third industry and beautiful cityscape.

\subsubsection{Aviation services, port logistics, headquarters economy-comprehensive construction of new regional service center}

During the process of the continuous introduction of companies and the continuous strengthen of airport economic zone, new regional service centers can be phased constructed. Taking into account of the level of the airport, with the location advantages of broad cooperation among Chaoshan metropolitan, Taiwan and asean countries, as well as the location conditions that this district is located in the center of the three cities, three new service types including aviation services, port logistics and headquarters economy should be planned and constructed in three stages, i.e. the near future, medium-term and long term, thereby meeting the modern industrial services needs of the airport and need of a new regional service center of Chaoshan metropolitan. (As shown in Table 4).

According to the second and the third industries of airport economic zone, our planning fully takes into account the close relationship between the industry and the airport as well as the local status, reasonable layout is made, thereby guaranteeing that the most valuable land is used for the most precious type of industry (as shown in Fig.4).

Table 2 The development time of the three engine of service centers in Eastern region of Guangzhou province

\begin{tabular}{|c|c|c|c|}
\hline Stage & Airpot service & Port logistics & Headquarters Economy \\
\hline The near future & $\begin{array}{l}1 \text { Improve aviation-related } \\
\text { basic services } \\
2 \text { Construct airlines } \\
\text { headquarters base }\end{array}$ & $\begin{array}{l}1 \text { construct port logistics } \\
\text { comprehensive supporting area } \\
2 \text { Apply to set up Chaoshan airport } \\
\text { bonded zone of "China-The ASEAN } \\
\text { free trade area" }\end{array}$ & $\begin{array}{l}\text { Leisure shopping industry: } \\
1 \text { Shopping Mall } \\
2 \text { Catering accommodation } \\
\text { 3The high-end professional market }\end{array}$ \\
\hline medium-term & $\begin{array}{l}1 \text { Construct industrial park } \\
\text { with aviation repair and } \\
\text { spare parts production } \\
2 \text { Construct aircraft technical } \\
\text { service institutions } \\
\end{array}$ & Construct the airport freight Village & $\begin{array}{l}1 \text { The business of financial industry } \\
2 \text { Convention and exhibition } \\
\text { industry }\end{array}$ \\
\hline long term & $\begin{array}{l}1 \text { construct air education and } \\
\text { training base } \\
2 \text { Construct aviation club }\end{array}$ & $\begin{array}{l}1 \text { construct aviation logistics business } \\
\text { service area } \\
2 \text { construct Aviation logistics } \\
\text { information platform }\end{array}$ & $\begin{array}{l}\text { Culture and entertainment industry } \\
1 \text { The leisure and entertainment } \\
\text { industry } \\
2 \text { Cultural and creative industries }\end{array}$ \\
\hline
\end{tabular}




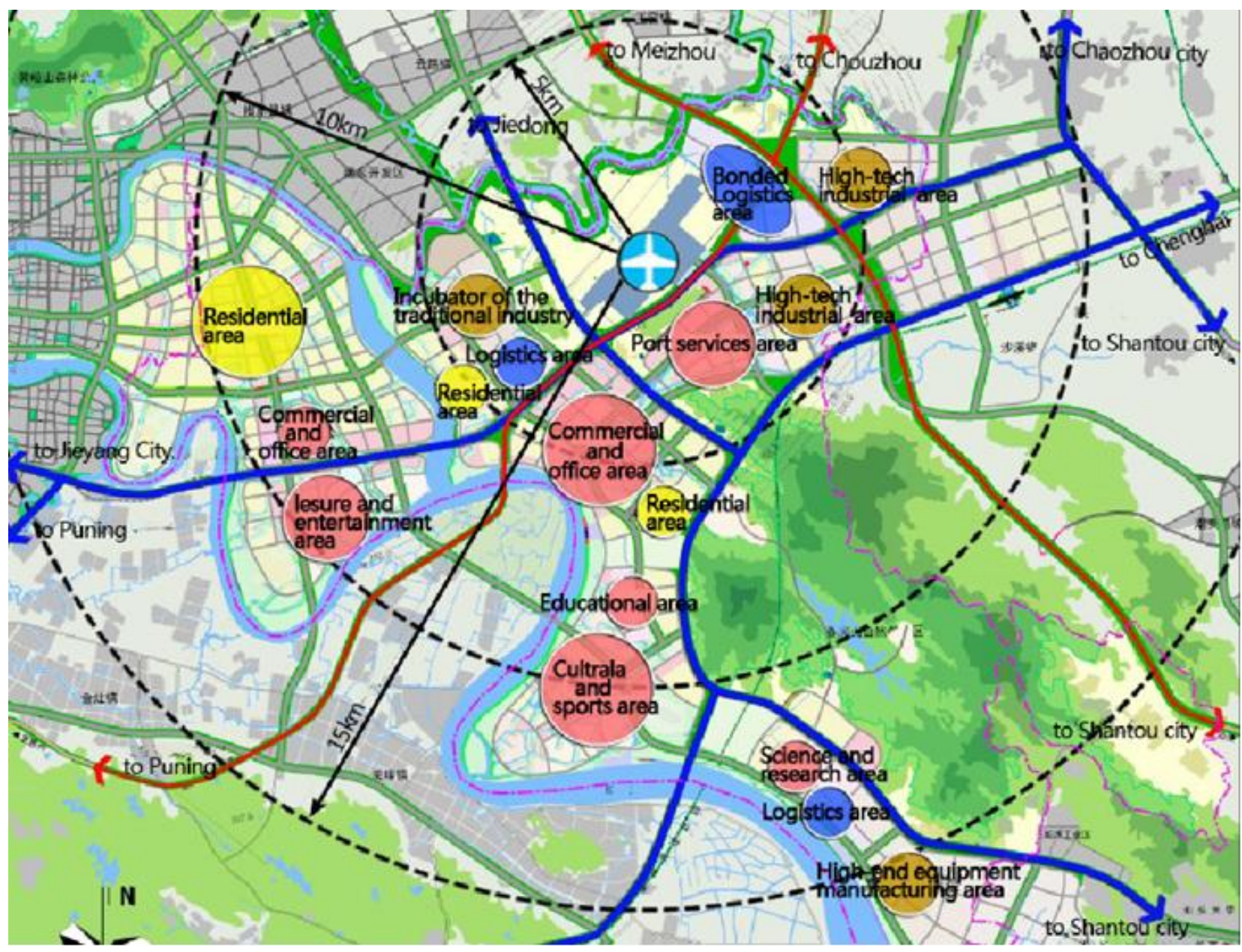

Figure 4 The layout structure of the Jieyang's industry

\section{CONCLUSION REMARKS}

The development of airport economy needs the comprehensive follow-up and layout of high levelindustry and service facilities, which will bring the city's industry a comprehensive upgrading, thereby leading the local economy to take off. However, some third-tier cities in the m-term industrial development stage and facing the problem of industrial structural transformation should do two things when the completion of the new airport at the regional level. On the one hand, it is necessary to firmly seize the opportunity of airport development and effectively introduce and high level industry, thereby promoting the upgrade of local industry and enhancing the city's position in the surrounding area. On the other hand, they should not divorce from reality, ignore that the interests of the local traditional industries need to continue to develop and squeeze the development space of local enterprises, and they should not overlook the links between existing downtown and free economic zone. They need to design innovative and effective ways, thereby integrating the development of traditional economy and new airport economy and making them complementary to each other, and share the development interests. In this way, the local economic benefits can be guaranteed and the stability of the city's existing economic pillars can be protected. Meanwhile, new economic entities can be introduced effectively, and grow rapidly under good economic condition, thereby driving the rapid upgrading of urban economy in the near future.

\section{REFERENCES}

[1] Fulong $\mathrm{Wu}$. "Re-orientation of the city plan: Strategic planning and design competition in China", Geoforum, Volume 38, Issue 2, March 2007, Pages 379-392.

[2] Healey, P. (1991). Urban regeneration and the development industry. Regional Studies, 25, 97-110.

[3] Healey, P., Davoudi, S., O'Toole, M., Usher, D., \& Tavsanoglu, S. (Eds.). (1992). Rebuilding the city, property-led urban regeneration. London: Spon Press.

[4] Harding, A. (1992). Property interests and urban growth coalitions in the UK: A briefencounter. InP. Healey, S. Davoudi, M. O'Toole, D. Usher, \& S. Tavsanoglu. (Eds.), Rebuilding the city, property-led urban regeneration. London: Spon Press

[5] Jieming Zhu. "Local Growth Coalition: The Context and Implications of China's Gradualist Urban Land Reforms "International Journal of Urban and Regional Research, Volume 23, Issue 3, pages 534-548, September 1999.

[6] Wu, F., 2002. China's changing urban governance in the transition towardsa more market-oriented economy. Urban Studies 39, 1071-1093.

[7] Zhu, J.M., 1999. Local growth coalition: the context and implications of China's gradualist urban land reforms. International Journal of Urban and Regional Research 23, 534-548. 